\section{THE SCARCITY OF WASPS}

$\mathrm{T}^{\mathrm{H}}$ $\mathrm{EE}$ correspondence in NATURE recently (October 12 and 26 and November 16) on the scarcity of wasps during the late summer and autumn of last year raises some interesting and difficult questions. In various parts of Great Britain-from. Wigtownshire, Cheshire, and Gloucestershire to Kent-this scarcity has been observed, following on an abundance of queens in spring. The wet and cold conditions prevailing in spring and early summer are suggested as the explanation by most of the writers who contributed observations, and this inclement weather would naturally be accompanied by a scarcity of the insects-caterpillars, greenfly, diptera, etc.on which wasps feed their grubs. In a letter to the West Kent Advertiser for November 24, Mr. G. W. Judge suggests that famine rather than cold was responsible for the mortality. Mr. W. F. Denning's definite observation (supra, p. 149) of the dying out of five nests of Vespa vulgaris near Bristol in June is noteworthy in this connection. Mr. A. O. Walker's theory that the queens of last year's spring were largely infertile would be difficult to support by observation. Mr. O. H. Latter ${ }^{1}$ has suggested that a mid-winter with much "open" weather-such as prevailed in January, I916-is deadly to queens by tempting them out of safe winter quarters. This cause can, however, scarcely be invoked to explain the paucity of autumn workers after a spring like that of 1916 , rich in queens.

The fact that worker wasps were abundant enough in some places makes it likely that other factors affecting the numbers of these insects still require investigation. Mr. H. St. G. Gray wrote (p. 209, supra) that they were too plentiful on the Somerset hills, and they certainly swarmed in the neighbourhood of Dublin during September. Referring to past records, I find that 1897 and 1907 were years marked by great scarcity of wasps in Ireland; the latter of these summers; at any rate, was abnormally wet and cool.

Most writers in NATURE and elsewhere express satisfaction at the temporary reduction in the wasp population. The damage done by wasps to fruit is undoubtedly great in normal seasons, and they also take a valuable portion of our foodsupply by their habit of robbing bee-hives of honey. On the other hand, as Mr. Latter and Mr. Denning point out, wasps are of considerable service in destroying multitudes of harmful insects, with which they feed their larvæ. The fierceness of wasps has been greatly exaggerated; unless attacked or annoyed, their disposition is placid, though one requires, perhaps, to be an admirer of the insects to be able to watch with serenity a dozen of them crawling over one's food. From the point of view of rural economy, it seems desirable to encourage wasps until the fruit season, and then to wage such war on them as may be found necessary.

Geo. H. Carpenter.

1 "Bees and Wasps" (Cambridge University Press), p. 44. NO. 2465 , VOL. 987

\section{NOTES}

ONE of the saddest incidents of the recent terrible explosion in a works engaged in refining explosives is the death of Mr. Andrea Angel, who was at the time acting as chief chemist and assistant-manager. The exact cause of the disaster is at present unknown, but it was preceded by an outbreak of fire. When the alarm was given, Mr. Angel, who was in his quarters, went at once to the scene of the fire and warned the operatives, many of whom undoubtedly owe their lives to his devotion to duty. Mr. Angel was born at Brad. ford in 1877 . He was educated at Exeter School, from which he went to Christ Church, Oxford, as an exhibitioner. He took a first class in chemistry in the Honour School of Natural Science in 1899, was afterwards elected Dixon research scholar, proceeded to the degree of M.A. in I903, and took the B.Sc. degree three years later. He acted for some years as lecturer in chemistry at Brasenose, and latterly at Christ Church, and was also tutor in chemistry to non-collegiate students. Shortly after the outbreak of war he gave up his work at Oxford and took up that on which he was engaged at the time of his tragic death. Mr. Angel was a fellow of the Chemical Society, and although the exacting duties of a college tutor left him little leisure for research, he was able to make several original contributions to the subject which have appeared in the Transactions of the society. He first published in 1902 , in conjunction with his tutor, Mr. Harcourt, "Observations on the Phenomena and Products of Decomposition when Normal Cupric Acetate is Heated," and afterwards papers on "Cuprous Formate" in Igo6 and on "The Isomeric Change of Halogen-substituted Diacylanilides into Acylaminoketones" in I9I2. He was a man of a very lovable and unselfish nature, and will be greatly mourned by a wide circle of friends and old pupils.

AN important letter from Lord Blyth appeared in the Times on January 22 emphasising the necessity for the close co-ordination of science with practice-in agriculture for the purpose of increasing the food production of the country. Lord Blyth's proposal is the immediate appointment of a Commission of men of science who shall devote their time exclusively to research in connection with the varying characteristics of the soil throughout the country, the crops most suited to each locality, the best methods of treating and manuring such land, the most suitable artificial manures to be used for each purpose, and the best substitutes for such of these as may be temporarily unobtainable by reason of scarcity or cost. As time is pressing the work should be put in hand at once and information promptly circulated through the War Agricultural Committees. This proposal will, we are sure, be received sympathetically on all sides, though, as a matter of fact, it is understood that such a Commission is already in process of formation. Throughout the war the agricultural colleges and experiment stations have rendered useful service, and have demonstrated more convincingly than ever the close connection between science and agriculture. Indeed, never before has agricultural science had so much recognition as now, either from farmers or from men engaged in pure science, and it is hoped that the new conditions will do much to strengthen still further the development of scientific agriculture in this country.

Particular attention is directed to the important letter which appears in another column from Prof. Eugenio Rignano, the well-known psychologist and editor of the Italian scientific monthly, Scientia. The question as to the establishment of year-books and international scientific jounnals in the countries of the 